\title{
DEMONSTRAÇÕES EM ÓPTICA GEOMÉTRICA: UMA PROPOSTA DE MONTAGEM PARA AMBIEN- TES DE EDUCAÇÃO NÃO FORMAL ${ }^{+*}$
}

Osmar Henrique Moura da Silva

Ferdinando Vinicius Domenes Zaparolli

Sérgio de Mello Arruda

Museu de Ciência e Tecnologia - UEL

Londrina - PR

\section{Resumo}

Centros de educação não formal, como museus de ciência e tecnologia (MCTs), comumente interessam em demonstrações cativantes em que os visitantes, por si só, interajam livremente no que se espera ser uma forma diferente e divertida de envolver o conhecimento cientifico. Este trabalho apresenta a montagem de um equipamento automatizado à energia elétrica padrão de $127 \mathrm{~V}$ que abrange as demonstrações de óptica geométrica costumeiramente realizadas com um raio de luz incidente em uma lente cilindroplano-convexa centrada em um círculo trigonométrico giratório. Dessa forma, contribui-se para a elaboração dessa alternativa tipicamente proveitosa para ambientes de educação não formal, bem como para quaisquer interessados nesse tipo de demonstração.

Palavras-chave: Óptica geométrica. Montagem de experimento. Centros de educação não formal.

\footnotetext{
Optical geometry demonstration: a proposal for non-formal education environment

* Recebido: setembro de 2012.

Aceito: outubro de 2012.
} 


\begin{abstract}
Centers of non-formal education, such as Science and Technology Museums, are commonly interested in engaging demonstrations in which visitors freely interact by themselves in what is expected to be a fun and different way to acquire scientific knowledge. This work presents an automated equipment to adapted standard $127 \mathrm{~V}$ electricity covering demonstrations of geometrical optics usually performed with a beam of light incident on a plan-convex lens focused on a trigonometric rotating circle. It contributes to the development of the alternative environments typically useful for non-formal education as any interested in this type of demonstration.
\end{abstract}

Keywords: Geometric Optics. Assembly experiment. Non-formal education centers.

\title{
I. Introdução
}

Ambientes planejados para a educação não formal (NRC, 2009), como museus de ciência e tecnologia (MCTs), usualmente apresentam equipamentos interativos expostos para visitação diária na intenção de dotar as atividades de aprendizagem de um caráter lúdico, o qual se pressupõe que estimule o interesse pelo conhecimento. Nessa perspectiva, uma equipe previamente capacitada auxilia pedagogicamente professores de todos os níveis de ensino, preocupando-se constantemente em ampliar e aprimorar suas demonstrações da área de exposição pública permanente, a fim de que a visitação seja um momento cada vez mais rico e intenso de aprendizagem. Dentro da perspectiva da aprendizagem por livre escolha (DIERKING, 2005), esses ambientes procuram possibilitar um livre passeio ao visitante, oferecendo atividades demonstrativas realizadas por ele próprio. Para isso, diversos equipamentos automatizados são desenvolvidos como sendo um seguro "brinquedo" com o propósito de gerar uma impressão divertida de abarcar o conhecimento científico, constituídos por comandos que conduzem o que fazer e observar, além de textos explicativos apropriados ao público-alvo. Assim elaborados, esses equipamentos ultrapassam o papel de experimentos de baixo custo para escolas sem laboratórios (CHINELLI et al., 2008, p. 4505-4509) e, quando conglomerados em atividades museais, complementando a educação científica formal (VALENTE et al., 2005, p. 198), é visível o impacto favorável nos participantes 
por gerar-se maior interesse por parte deles em saber mais sobre algum tema exposto após participação nas atividades (PEREIRA et al., 2008, p. 100).

$\mathrm{Na}$ intenção de contribuir para aqueles comprometidos com a educação científica não formal, o presente trabalho divulga a elaboração de um equipamento de óptica geométrica no qual se orientam as demonstrações sendo simplesmente controladas pelo acionamento de dois botões. Especificamente, o equipamento apresenta automatização adaptada à energia elétrica padrão de $127 \mathrm{~V}$ e envolve as demonstrações físicas corriqueiramente feitas com um raio de luz incidente em uma lente cilindro-plano-convexa centralizada em um círculo trigonométrico giratório.

\section{Materiais utilizados e construção do equipamento}

Para facilitar a orientação dessa construção, apresentam-se três subseções relacionadas assim denominadas: o arranjo experimental do raio de luz incidente na lente cilindro-plano-convexa; a automatização por circuito eletrônico; e a montagem final. Nessa última também se inclui um modelo criado referente ao comando de orientação com textos explicativos dos fenômenos.

\section{II.1 O arranjo experimental do raio de luz incidente na lente cilindro-plano- convexa}

Detalha-se nesta etapa a montagem que se apropria dos materiais necessários à geração do fenômeno de incidência de um raio de luz no centro de uma lente cilindro-plano-convexa giratória com angulação controlável. Esses materiais são: 1 laser verde ${ }^{2}$ com potência aproximada de $500 \mathrm{~mW}$ e $3 \mathrm{~V}$ (DC); 1 lente cilindroplano-convexa caracterizada por um semicírculo de acrílico (ou vidro) com diâmetro próximo de $10 \mathrm{~cm}$ e $1 \mathrm{~cm}$ de espessura; 1 cilindro maciço de vidro de $4 \mathrm{~cm}$ de comprimento e $1 \mathrm{~cm}$ de diâmetro; 1 pequeno motor elétrico cilíndrico de baixa velocidade de rotação com tensão de funcionamento próxima dos $24 \mathrm{~V}$ (DC); um disco de acrílico com diâmetro próximo de $20 \mathrm{~cm}$ de diâmetro com $1 \mathrm{~cm}$ de espessura contendo um desenho de círculo trigonométrico fixado em uma das superfícies; 1 rolamento de aço de $3 \mathrm{~cm}$ de diâmetro externo (com eixo de ferro de $3 \mathrm{~cm}$ )

\footnotetext{
${ }^{1}$ Do museu de ciência e tecnologia da instituição onde se encontram os autores.

2 Também se pode usar um laser vermelho com potência aproximada de $5 \mathrm{~mW}$ e 4,5 V (DC).
} 
para ser fixado no centro de uma das roldanas (a maior); 2 roldanas pequenas (de acrílico, madeira ou metal): uma, com diâmetro de $7 \mathrm{~cm}$, a ser fixada abaixo do disco de acrílico juntamente com o rolamento, e outra, com diâmetro de $3 \mathrm{~cm}$, a ser adaptada ao eixo do motor elétrico; 1 correia com diâmetro de $3 \mathrm{~mm}$ adaptada às roldanas; 1 chapa de ferro em formato L que será fixada na caixa (ver Fig. 2); 1 abraçadeira para prender o motor à chapa em formato $\mathrm{L}$.

De início, como o laser originalmente funciona por meio de pilhas, soldam-se (com estanho) dois fios condutores em seus terminais internos (polos) para que ele possa ser alimentado pelo circuito eletrônico, seguindo o esquema da próxima subseção. Nesse arranjo, a lente cilindro-plano-convexa é fixada no centro do desenho de círculo trigonométrico, usando fita adesiva transparente dupla face. Já o cilindro de vidro de $4 \mathrm{~cm}$ precisa estar disposto de modo que o laser o atravesse transversalmente para produzir o raio de luz visível na superfície de observação (disco giratório), conforme se ilustra na Fig. $1^{3}$. Nesta figura, o motor de formato cilíndrico (que também será ligado no circuito eletrônico) apresenta uma roldana acoplada na extremidade inferior, escondida na figura, sendo o mesmo para a roldana do disco. A Fig. 2 representa uma visão lateral que permite melhor orientar a adequação dessas roldanas com a correia.

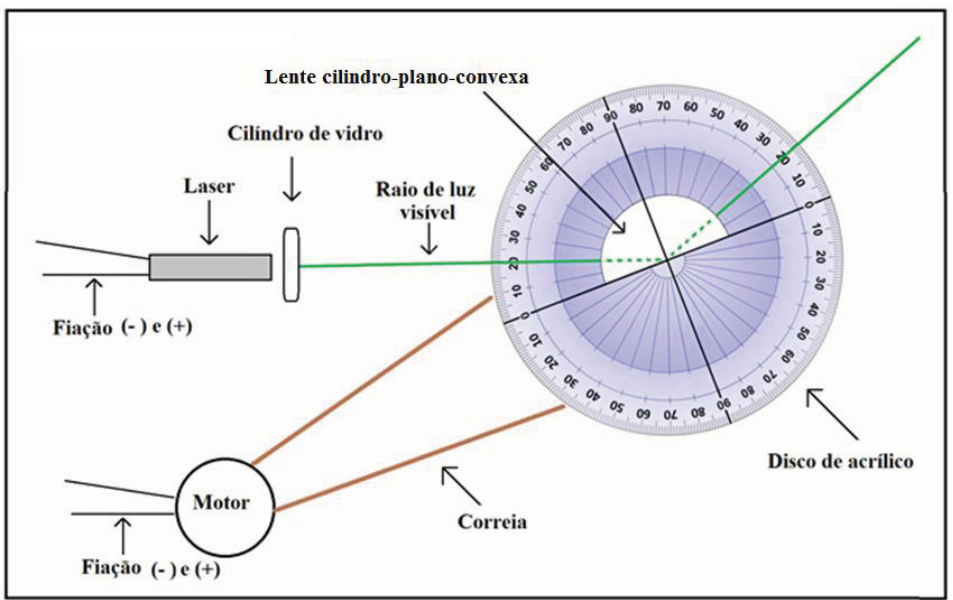

Fig. 1 - Arranjo experimental entre o laser e a lente com vista frontal do disco giratório.

\footnotetext{
3 Devido à sua dimensão indicada, a função deste cilindro é permitir uma determinada refração que diverge o feixe do laser ao atravessá-lo. Com isso, gera-se um raio e uma luz que percorre toda uma superfície desejada às demonstrações.
} 
Na Fig. 2 é possível observar a chapa de ferro em formato L, parafusada na base da caixa da montagem final. Nessa chapa, prende-se o motor com a abraçadeira. Vê-se, também, que a roldana menor é encaixada no eixo do motor com posicionamento vertical em relação à base. A roldana maior encontra-se fixada (colada ou parafusada) na parte inferior do disco e possui em si própria, internamente centrado, o rolamento com eixo de ferro encaixado. A extremidade restante desse eixo é fixada na base.

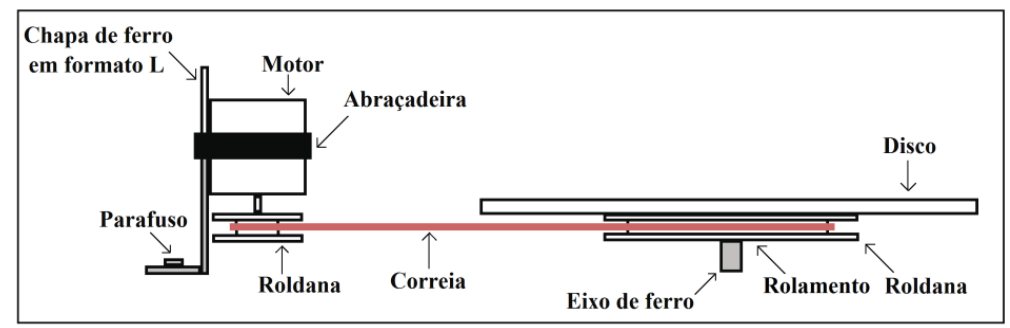

Fig. 2 - Visão da adaptação das roldanas e da correia.

\section{II.2 A automatização por circuito eletrônico}

A automação se beneficia de um dispositivo para controlar tanto a demonstração em si quanto o seu desligamento com tempo programado. Os componentes necessários ao circuito eletrônico são:

1 placa de circuito impresso de $(16 \times 10) \mathrm{cm}$;

1 transformador $127 \mathrm{~V}$ para $12 \mathrm{~V}$ (entre 1 a $0,5 \mathrm{~A}$ );

2 diodos IN 4007;

1 capacitor de $1000 \mu \mathrm{F}$ de $16 \mathrm{~V}$;

1 capacitor de $20 \mu \mathrm{F}$ de $16 \mathrm{~V}$;

1 capacitor de $10 \mu \mathrm{F}$ de $16 \mathrm{~V}$;

1 chave liga-desliga;

2 botões push-button (tipo NA);

1 resistor de $1 \mathrm{M} \Omega$;

1 resistor de $22 \mathrm{~K} \Omega$;

1 resistor de $1 \mathrm{~K} \Omega$;

1 transistor BC548;

1 relé de $12 \mathrm{~V}$;

1 CI 555;

1 fio duplo com pino macho para ligação na tomada; 
1 fonte de $5 \mathrm{~V}(\mathrm{DC})$ frequentemente usada para carregar baterias de celulares;

2 potenciômetros pequenos de fio com cerca de $300 \Omega$.

A Fig. 3 apresenta o esquema elétrico para se desenhá-lo na placa de circuito impresso com caneta apropriada, mergulhando, então, essa placa em solução de percloreto de ferro para remoção do cobre da superfície que não está marcada. Posteriormente, retira-se a tinta das trilhas desenhadas nessa superfície, lixando-as com lã de aço. Para finalizar essa etapa da montagem, fazem-se os devidos furos para o encaixe dos componentes, soldando-os nas trilhas de cobre ${ }^{4}$.

Ao completar as ligações procedentes na Fig. 3, o dispositivo de controle está destinado a ligar o laser por aperto de um dos botões e desligá-lo automaticamente, permitindo também, no aperto do outro botão, girar o disco e, com isso, controlar o ângulo de incidência do raio de luz na lente cilindro-plano-convexa. $\mathrm{O}$ tempo do desligamento do laser é diferido ao se alterar o capacitor de $20 \mathrm{uF}$, que pode, inclusive, ser trocado por um capacitor variável, cujo valor da escala dependerá do interesse em ajustar o tempo de funcionamento do laser. Com a ligação em série do potenciômetro, entre a fonte de $5 \mathrm{~V}$ e o laser, permite-se ajustar a tensão fornecida a esse último para o limite de $3 \mathrm{~V}$, mas com possível alteração dessa tensão e, por conseguinte, da intensidade do raio de luz segundo a visualização desejada. Já para o giro do disco, ele sempre ocorrerá enquanto o botão relacionado estiver pressionado, tendo-se pré-definida sua velocidade de rotação por uma regulagem do outro potenciômetro, correspondente ao motor no circuito (Fig. 3). Sugere-se, nessa regulagem, estabelecer uma velocidade de rotação do disco de modo que o experimentador consiga, com ligeiros apertos no botão, avançar de grau em grau durante um pretendido estudo minucioso dos fenômenos. Como opcional, acrescenta-se uma chave liga-desliga para deixar o equipamento permanentemente conectado à tomada.

\footnotetext{
${ }^{4}$ Pode-se substituir esse método mais tradicional já partindo de uma placa de circuito impresso perfurada (pré-furada) de 160x100 mm, onde se encaixam os componentes citados, realizando as ligações com fios tipo cabinho e solda estanho.

${ }^{5}$ Nessa finalidade, pode-se, também, manter o capacitor de $20 \mathrm{uF}$ e trocar o resistor de 1 $\mathrm{M} \Omega$ por um resistor variável (trimpot).
} 


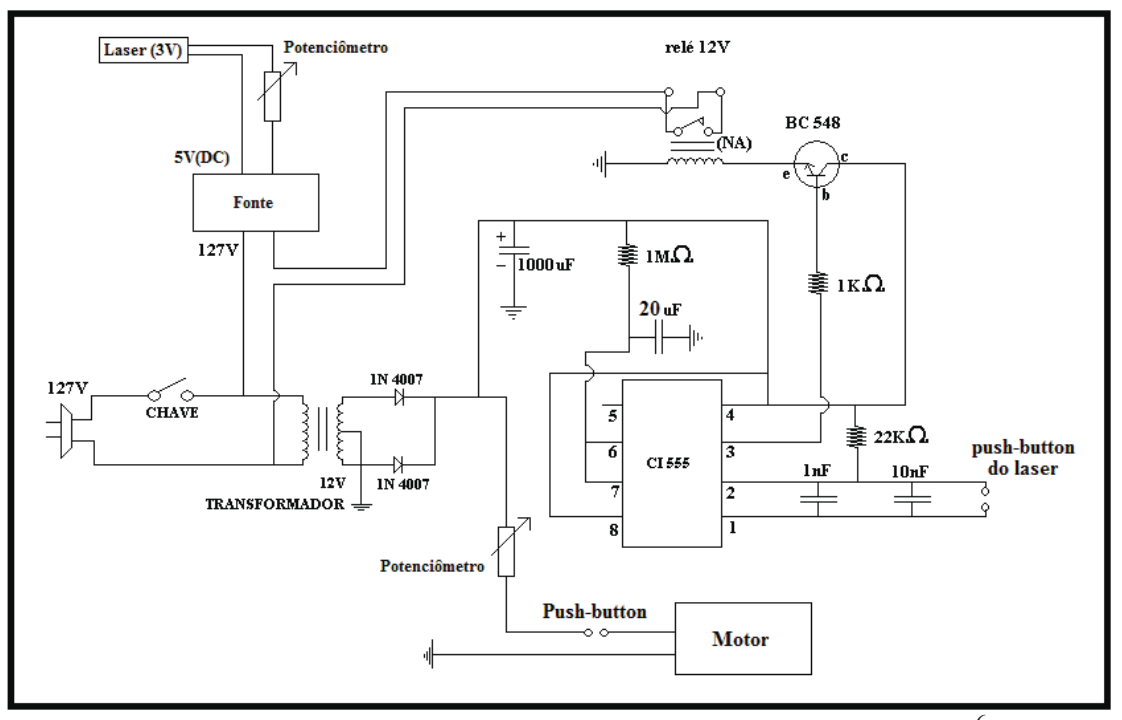

Fig. 3 - Esquema elétrico do circuito de controle automático ${ }^{6}$.

\section{II.3 A montagem final}

As demonstrações desta proposta ocorrem com o equipamento fixado em uma parede. Para isso, uma caixa de acrílico com dimensões de $(40 \times 25 \times 10) \mathrm{cm}$, chapa de $1 \mathrm{~cm}$ de espessura, deve ser montada para que nela sejam interiorizados os elementos já preparados, tendo-se uma divisória (também de chapa de acrílico) separando o disco giratório do resto. A caixa pode ser interna e externamente pintada de preto para esconder os vários itens que, de um lado, apenas os dois botões de controle da demonstração são expostos, mantendo-se o outro lado com a frente transparente para observação interna (Fig. 4). Internamente, no lado esquerdo da Fig. 4, o laser e o tubo de vidro de $4 \mathrm{~cm}$ são seguros por arames usando cola epóxi, válida também para fixar os potenciômetros, posicionando-se os demais elementos ou com essa cola ou com parafusos. É importante perceber na Fig. 4 que a divisória necessita ter três furos: um para a passagem do raio de luz e outros dois para o percurso da correia. Externamente à caixa ${ }^{7}$, adapta-se a chave liga-desliga incluindo-se um furo de saída para a fiação a ser ligada na tomada de $127 \mathrm{~V}$. Como a

\footnotetext{
${ }^{6}$ Desenvolvimento alcançado por ideias em Saber Eletrônica $<$ http://www.sabereletronica.com.br/secoes/leitura/1595>.

${ }^{7}$ Esteticamente, sugere-se na lateral esquerda da Fig. 4.
} 
caixa tem $40 \mathrm{~cm}$ de largura, pode-se parafusar uma barra de ferro de $(60 \times 3) \mathrm{cm}(3$ $\mathrm{mm}$ de espessura) centralizada atrás dela, em que os $10 \mathrm{~cm}$ restantes de cada lado são furados para fixar, com parafusos, a estrutura no local determinado.

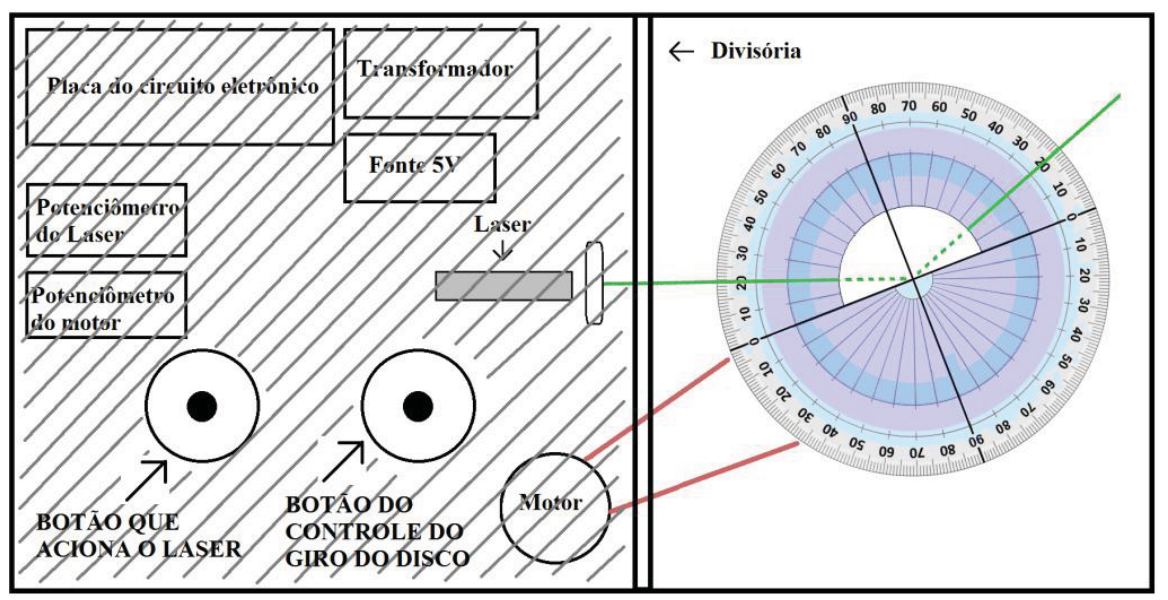

Fig. 4 - Caixa montada com duas partes separadas por divisória: No lado esquerdo (área rasurada) da divisória estão os elementos internamente escondidos na caixa com os dois botões de controle aparentes. No lado direito tem-se visualização interna para observação dos fenômenos.

Assim concluída essa etapa da montagem, a preocupação se refere às orientações de funcionamento com textos explicativos dos fenômenos. Fisicamente, as demonstrações possíveis de óptica geométrica relacionam-se à lei de SnellDecartes (HALLIDAY et al., 1995), e que, devido à geometria da lente utilizada, além dos conceitos de refração, abarcam-se os de ângulo limite e reflexão total. Considerando isso, tais orientações aqui elaboradas se encontram detalhadas em anexo e devem ser entendidas como um exemplo do que pode ser empregado no equipamento (foto da Fig. 5), objetivando orientar os visitantes a interagirem livremente com ele na intenção de prover um envolvimento com o conhecimento científico dentro da perspectiva seguida em espaços educativos não formais. 


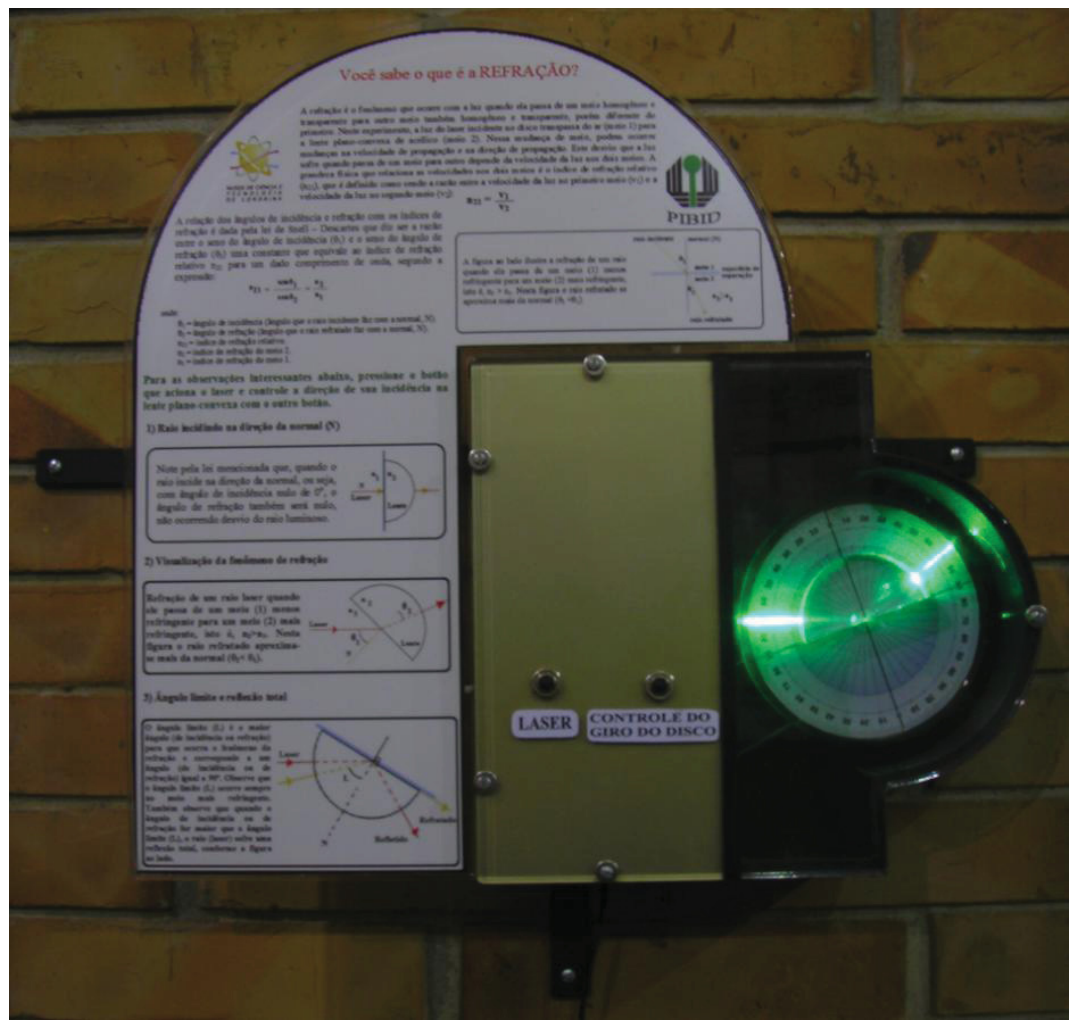

Fig. 5 - Foto do equipamento finalizado, disponível para experimentação em uma área de exposição pública do MCT, podendo-se notar o design geral ${ }^{8}$ da montagem que incluem os comentários do anexo.

\section{Considerações finais}

Este trabalho contribuiu para fornecer uma montagem de um equipamento de óptica geométrica tipicamente proveitosa para ambientes de educação não formal como para quaisquer interessados nesse tipo de demonstração. $\mathrm{O}$ equipamento da Fig. 5 se localiza fixado em uma das paredes do MCT da instituição de ensino superior em que os autores se encontram, atendendo à comunidade externa já há

${ }^{8}$ Particularmente, preferiu-se deixar a lateral direita da caixa curvada, acompanhando a forma do disco giratório. 
dois anos em funcionamento. A montagem é inovadora e permite que as demonstrações se tornem muito práticas pela automatização acrescentada. Como se viu, o equipamento explora as demonstrações relacionadas à lei de Snell-Decartes com ângulo limite entre reflexão total e refração. Entretanto, o texto explicativo em anexo constitui um exemplo que pode ser aperfeiçoado ${ }^{9}$ a critério do aprofundamento determinado nas explicações físicas em termos qualitativos ou não, indo-se atrás de informações de qualidade e quantidade que se julguem necessárias nas demonstrações; tudo isso, obviamente, pensando-se em uma linguagem adequada ao público almejado.

Este trabalho faz parte de um plano de divulgação das atividades do projeto PIBID/UEL na região de Londrina.

\section{Agradecimentos}

À CAPES e ao CNPq pelo apoio financeiro.

\section{Referências}

CHINELli, M. V.; PEREIRA, G. R.; AGUIAR, L. E. V. Equipamentos interativos: uma contribuição dos centros e museus de ciências contemporâneos para a educação científica formal. Revista Brasileira de Ensino de Física, v. 30, n. 4, 2008 .

DIERKING, L. D. Lessons without limit: how free-choice learning is transforming science and technology education. História, Ciências, Saúde, v. 12 (supplement), p. 145-160, Manguinhos, 2005.

HALLIDAY, D.; RESNICK, R.; WALKER, J. Fundamentos de Física. 4. ed. Rio de Janeiro: LTC, 1995. v. IV

NATIONAL RESEARCH COUNCIL. Learning science in informal environments: people, places, and pursuits. Committee on learning science in informal environments. BELL, P.; LEWENSTEIN, B.; SHOUSE, A. W.; FEDER, M. A. (Eds.). Board on science education, center for education. Division of behavioral and

\footnotetext{
9 Aliás, ainda que qualquer elaboração deste tipo esteja sempre limitada e alvo de melhorias, é significativo dizer que a essência desta proposta educacional que segue o equipamento mantém-se conservada.
} 
social sciences and education. Washington, DC: The National Academies Press, 2009.

PEREIRA, G. R.; CHINELli, M. V.; COUTINHO-SILVA, R. C. Inserção dos centros e museus de ciências na educação: estudo de caso do impacto de uma atividade museal itinerante. Ciência \& Cognição, v. 13, n. 3, p. 100-119, 2008.

SABER ELETRÔNICA: o seu portal para o universo da eletrônica - on-line. Disponível em: <http://www.sabereletronica.com.br/secoes/leitura/1595>. Acesso: em 31 ago. 2012.

VALENTE, M. E.; CAZELLI, S.; ALVES, F. Museus, ciência e educação: novos desafios. História, Ciências, Saúde, v. 12 (supplement), p. 183-203, Manguinhos, 2005 .

\section{Anexo}

\section{Você sabe o que é a REFRAÇÃO?}

A refração é o fenômeno que ocorre com a luz quando ela passa de um meio homogêneo e transparente para outro meio também homogêneo e transparente, porém diferente do primeiro. Neste experimento, a luz do laser incidente no disco transpassa do ar (meio 1) para a lente cilindro-plano-convexa de acrílico (meio 2). Nessa mudança de meio, podem ocorrer mudanças na velocidade de propagação e na direção de propagação. Este desvio que a luz sofre quando passa de um meio para outro depende da velocidade da luz nos dois meios. A grandeza física que relaciona as velocidades nos dois meios é o índice de refração relativo $\left(\mathrm{n}_{21}\right)$, que é definido como sendo a razão entre a velocidade da luz no primeiro meio $\left(\mathrm{v}_{1}\right)$ e a velocidade da luz no segundo meio $\left(\mathrm{v}_{2}\right)$ :

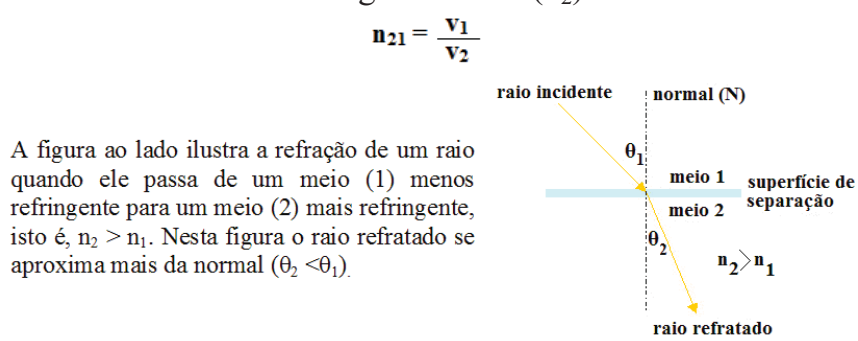

\footnotetext{
${ }^{10}$ Texto modelo para conduzir o visitante em o que fazer e observar durante uma experimentação. As fotos acrescentadas aos comentários e desenhos são uma sugestão.
} 
A relação dos ângulos de incidência e refração com os índices de refração é dada pela lei de Snell - Descartes que diz ser a razão entre o seno do ângulo de incidência $\left(\theta_{1}\right)$ e o seno do ângulo de refração $\left(\theta_{2}\right)$ uma constante que equivale ao índice de refração relativo $\mathrm{n}_{21}$ para um dado comprimento de onda, segundo a expressão:

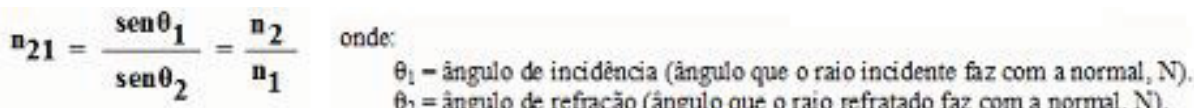

$$
\begin{aligned}
& \theta_{2}=\text { ângulo de refração (ângulo que oraio refratado faz com a normal, } N \text { ). } \\
& \mathrm{n}_{21}=\text { indice de refraço relativo. } \\
& \mathrm{n}_{2}=\text { indice de refração do meio } 2 \text {. } \\
& \mathrm{n}_{1}=\text { indice de refraçăo do meio } 1 .
\end{aligned}
$$

Para as observações interessantes abaixo, pressione o botão que aciona o laser e controle a direção de sua incidência na lente cilindro-plano-convexa com o outro botão.

\section{1) Raio incidindo na direção da normal (N)}

Note pela lei mencionada que, quando o raio incide na direção da normal, ou seja, com ângulo de incidência nulo de $0^{\circ}$, o ângulo de refração também será nulo, não ocorrendo desvio do raio luminoso.

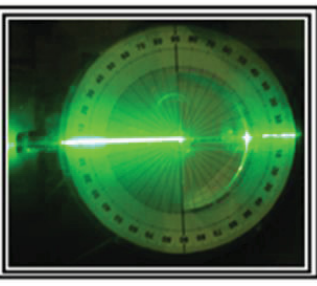

\section{2) Visualização do fenômeno de refração}

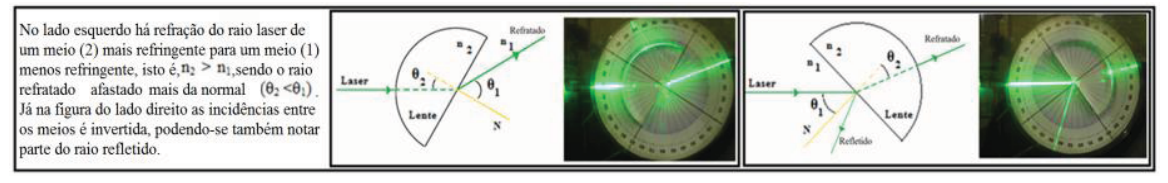

\section{3) Ângulo limite e reflexão total}

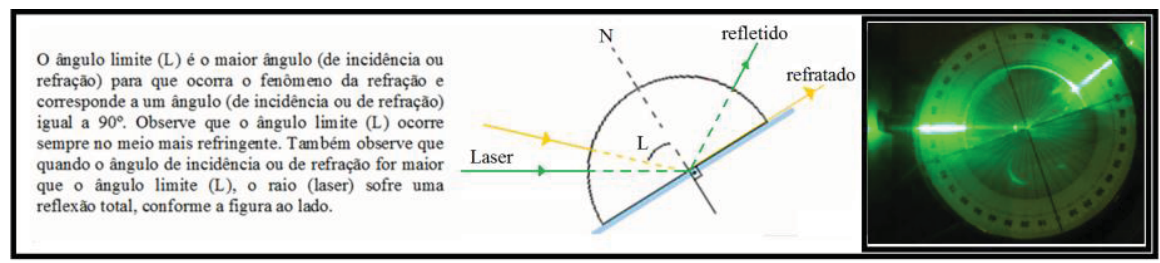

